\title{
Abortamento de frutos da nogueira macadâmia sob influência da adubação mineral ${ }^{1}$
}

\author{
Marcos José Perdoná ${ }^{2}$, Eduardo Suguino ${ }^{3}$, Adriana Novais Martins ${ }^{4}$, Rogério Peres Soratto ${ }^{5}$
}

\section{RESUMO}

A nogueira macadâmia (Macadamia integrifolia) apresenta elevada taxa de abortamento de frutos. A nutrição desequilibrada pode ser um dos fatores que contribui para isso. Objetivou-se, com esta pesquisa, avaliar a influência de doses de N e do parcelamento da adubação NPK, de cobertura, na redução do abortamento de frutos da nogueira macadâmia. Foram desenvolvidos dois experimentos, durante três anos agrícolas, num Latossolo Vermelho, em Jaboticabal, Estado de São Paulo. O primeiro experimento foi constituído por cinco doses de N (0, 50, 100, 150 e $200 \mathrm{~kg}$ $\mathrm{ha}^{-1} \mathrm{ano}^{-1}$ ) e quatro repetições. O segundo experimento foi constituído por quatro formas de parcelamento da adubação NPK (T1: outubro T2: outubro + dezembro, T3: outubro + dezembro + fevereiro e T4: outubro+dezembro + fevereiro + abril) e cinco repetições. A maior parte dos frutos (77,7 \%) foi abortada no início de seu desenvolvimento. A aplicação de N, bem como o parcelamento da adubação NPK de cobertura, pelo menos em duas vezes (outubro e dezembro), não alteraram o número de frutos abortados por planta de macadâmia, mas, por aumentarem o número total de frutos emitidos e reduzirem a percentagem de abortamento, proporcionaram maior produtividade de nozes.

Palavras-chave: Macadamia integrifolia, nutrição, parcelamento da adubação, abscisão.

\begin{abstract}
Macadamia nut abortion as affected by mineral fertilization

Macadamia (Macadamia integrifolia) has a high nut abortion rate. Unbalanced nutrition may be one of the factors that contributes to this problem. The aim of this study was to evaluate the influence of $\mathrm{N}$ doses and the split application of NPK fertilizers on fruit abortion of macadamia nut. Two experiments were conducted during three growing seasons on an Oxisol, in Jaboticabal, São Paulo State, Brazil. The first experiment consisted of five N rates (0, 50, 100,150 and 200 $\mathrm{kg} \mathrm{ha}^{-1} \mathrm{yr}^{-1}$ ) and four replications. The second experiment consisted of four splitting modes of NPK fertilizers (T1: October, T2: October + December, T3: October + December + February and T4: October + December + February + April) and five replications. Most fruits $(77.7 \%)$ aborted earlier in their development. The $\mathrm{N}$ application and the split fertilization of NPK as topdress for at least twice (October and December), did not affect the number of aborted fruits per macadamia tree, but, by increasing the total number of set fruits and reducing the percentage of abortion, provided higher nut productivity.
\end{abstract}

Key words: Macadamia integrifolia, nutrition, split fertilization, abscission.

Recebido para publicação em 08/04/2013 e aprovado em 14/08/2013.

${ }^{1}$ Trabalho financiado pela Agência Paulista de Tecnologia dos Agronegócios e Associação Brasileira de Noz Macadâmia.

${ }^{2}$ Engenheiro-Agrônomo, Doutor. Agência Paulista de Tecnologia dos Agronegócios, Regional Centro Oeste, Avenida Rodrigues Alves, 40-40, 17030-000, Bauru, São Paulo, Brasil. marcosperdona@apta.sp.gov.br (autor para correspondência).

${ }^{3}$ Engenheiro-Agrônomo, Doutor. Agência Paulista de Tecnologia dos Agronegócios, Regional Centro Leste, Avenida Bandeirantes, 2419, 14030-670, Ribeirão Preto, São Paulo, Brasil. esuguino@apta.sp.gov.br

${ }^{4}$ Engenheira-Agrônoma, Doutora. Agência Paulista de Tecnologia dos Agronegócios, Regional Centro Oeste, Rua Andrade Neves, 81, 17515-400, Marília, São Paulo, Brasil. adrianamartins@apta.sp.gov.br

${ }^{5}$ Engenheiro-Agrônomo, Doutor. Departamento de Produção e Melhoramento Vegetal, Universidade Estadual Paulista, Faculdade de Ciências Agrárias, Universidade Estadual Paulista, Campus Botucatu, Fazenda Experimental Lageado, s/n, 18610-307, Botucatu, São Paulo, Brasil. Bolsista de Produtividade em Pesquisa do CNPq. soratto@ fca.unesp.br 


\section{INTRODUÇÃO}

A nogueira macadâmia (Macadamia integrifolia Maiden e Betche) é nativa das florestas tropicais costeiras do sul dos estados de Queensland e Nova Gales do Sul, na Austrália, porém, desenvolve-se melhor em regiões de clima subtropical. É a única planta australiana cultivada comercialmente para produção de alimentos e sua semente é considerada por muitos a mais saborosa noz do mundo (Huett, 2004; Sacramento \& Pereira, 2003).

O Brasil, com área de, aproximadamente, 6.000 hectares cultivados com macadâmia, é o sétimo maior produtor mundial, com a produção concentrada nos Estados de São Paulo (33 \%), Espírito Santo (31\%), Bahia (18\%) e Rio de Janeiro (10 \%). A partir de 2005, mais de uma dezena de indústrias instalaram-se no interior de São Paulo, para atender ao mercado interno, em franca expansão (Sobierajski et al., 2006; Perdoná \& Suguino, 2008).

Técnicas como enxertia e propagação "in vitro" são utilizadas para melhorar a uniformidade e vigor das plantas (Dalastra et al., 2010; Cha-um et al., 2011), mas a produtividade das lavouras de macadâmia ainda é muito variável, desde 4,9 a $125 \mathrm{~kg}$ planta $^{-1}$ (Pimentel et al., 2007; Rojas et al., 2009). Uma planta adulta pode produzir 10.000 racemos, com 100 a 300 flores em cada um deles e, apesar de as plantas sempre exibirem floradas exuberantes, as produtividades das lavouras são baixas, pois somente 0,3 $\%$ das flores tornam-se frutos maduros e um grande número de racemos não forma frutos (Sobierajski et al., 2007). Sobierajski et al. (2006), analisando dados de uma cooperativa de produtores, localizada no Estado do Espírito Santo, aferiram que a produtividade média de noz na região estava entre 10 e $12 \mathrm{~kg}$ planta $^{-1}$. No estado de São Paulo são 150 produtores, 1.927 ha, com produtividade média de 12,2 $\mathrm{kg}_{\text {planta }}{ }^{-1}$ (Cati, 2008), bastante inferiores àquelas relatadas na literatura, consideradas como o principal fator responsável pela rentabilidade negativa da cultura.

Um dos fatores que contribui para a baixa produtividade é a ocorrência de altas taxas de abortamento prematuro de frutos. A abscisão de frutos jovens inicia-se nas primeiras três semanas após a antese, no início da primavera, e continua até nove e dez semanas após (McFadyen et al., 2011). Ovários de frutos abortados não apresentam diferenças dos ovários dos frutos retidos pelas plantas; assim, a queda prematura de frutos é um problema fisiológico, causado provavelmente pela ineficiência da distribuição de água e nutrientes em fases específicas do ciclo (McFadyen et al., 2012).

Diversos fatores podem influenciar a queda prematura de frutos: seca, frio, calor, inundações, nebulosidade, lesões, doenças, infestação de pragas e, entre eles, o desequilíbrio nutricional. Para Stephenson et al. (1997), altas produtividades de nozes estão associadas a quanti- dades equilibradas de nitrogênio $(\mathrm{N})$ e recomendam até 1 $\mathrm{kg}$ planta $^{-1}$ ano $^{-1}$ de ureia. No Brasil, são recomendados 50 $\mathrm{kg} \mathrm{ha}^{-1} \mathrm{ano}^{-1}$ de $\mathrm{N}$, para lavouras com produção de até 5 $\mathrm{Mg} \mathrm{ha}^{-1} \mathrm{ano}^{-1}$ e a faixa adequada para teores foliares de $\mathrm{N}$ é de 15 a $25 \mathrm{~g} \mathrm{~kg}^{-1}$ (Raij et al., 1997). Na Austrália, doses superiores a $100 \mathrm{~kg} \mathrm{ha}^{-1} \mathrm{ano}^{-1}$ de $\mathrm{N}$ são utilizadas pelos produtores (Fletcher et al., 2009) e a faixa considerada ideal, para teores foliares de $\mathrm{N}$, é de 14 a $15 \mathrm{~g} \mathrm{~kg}^{-1}$ (Stephenson \& Cull, 1986).

A planta de macadâmia apresenta fluxos de vegetação e uma vigorosa rebrota é capaz de provocar alto índice de abortamento e redução substancial da produtividade (Olesen, 2005; McFadyen et al., 2011). Para Stephenson \& Cull (1986), o fator que mais influi para ocorrência de fluxos de vegetação é a temperatura, porém, a aplicação de fertilizantes nitrogenados pode afetar o grau de vegetação, podendo inibir a produção, principalmente nos estádios iniciais de desenvolvimento dos frutos. Assim, adubações com $\mathrm{N}$, em fases específicas, podem exercer grande influência na produtividade final da cultura (Stephenson \& Gallagher, 1989). Dessa forma, estudos que relacionem as doses de $\mathrm{N}$ aplicadas e o parcelamento das adubações com o abortamento prematuro de fruto irão colaborar na formação de conceitos necessários para construção de adequadas recomendações.

Objetivou-se, com esta pesquisa, avaliar a influência de doses de $\mathrm{N}$ e do parcelamento da adubação NPK, de cobertura, no abortamento de frutos da nogueira macadâmia.

\section{MATERIAL E MÉTODOS}

Foram desenvolvidos dois experimentos, no município de Jaboticabal, SP (21 $08^{\circ} \mathrm{S}, 48^{\circ} 11^{\prime} \mathrm{O}$, a $583 \mathrm{~m}$ de altitude). Segundo a classificação de Köeppen, o clima da região é do tipo Aw, tropical com estação seca, apresentando temperatura média anual de $23,2^{\circ} \mathrm{C}$ e precipitação pluvial de $1405 \mathrm{~mm}$.

O solo é classificado como Latossolo Vermelho não férrico, eutrófico, de textura média, cujos atributos químicos de amostras coletadas nas faixas onde são aplicadas as adubações, na camada de 0-20 cm de profundidade, antes da instalação do experimento, foram: $15 \mathrm{~g} \mathrm{dm}^{-3} \mathrm{de}$ matéria orgânica $\mathrm{pH}$ em $\mathrm{CaCl}_{2}$ de $5,4,17 \mathrm{mg} \mathrm{dm}^{-3}$ de $\mathrm{P}$ (extrator resina) 2,9, 11,9 e 32,9 $\mathrm{mmol}_{\mathrm{c}} \mathrm{dm}^{-3} \mathrm{de} \mathrm{K}, \mathrm{Ca}, \mathrm{Mg}$ e CTC, respectivamente, saturação por bases de $70 \%$ e 21 $\mathrm{mg} \mathrm{dm}^{-3} \mathrm{de} \mathrm{S}_{-} \mathrm{SO}_{4}{ }^{2-}$. Antes do início do estudo, os teores foliares de $\mathrm{N}$, fósforo $(\mathrm{P})$ e potássio $(\mathrm{K})$, determinados de acordo com metodologia descrita por Malavolta et al. (1997), eram de 14,2, 0,85 e 8,6 $\mathrm{g} \mathrm{kg}^{-1}$, respectivamente.

Os experimentos foram iniciados em outubro de 2008 e conduzidos durante três anos agrícolas (2008/2009, 2009/2010 e 2010/2011). As plantas, da variedade HAES 
344, de origem havaiana, enxertadas sobre porta-enxerto Aloha IAC 10-14, foram plantadas no ano de 1998, no espaçamento $8 \mathrm{~m}$ x $6 \mathrm{~m}$. Desde o plantio até o início dos experimentos, o manejo de adubações seguiu as recomendações de Raij et al. (1997), considerando-se produtividade esperada de até $5 \mathrm{Mg} \mathrm{ha}^{-1}$, na fase de produção. No período em que se realizaram os experimentos, as plantas eram adultas, apresentavam bom vigor e produziram, no ano anterior à instalação dos experimentos (2007/2008), 12,8 kg de nozes planta ${ }^{-1}$, em média, produção considerada adequada pelos produtores do Estado de São Paulo.

O experimento I foi instalado em delineamento de blocos casualizados, com cinco doses de $\mathrm{N}(0,50,100,150 \mathrm{e}$ $200 \mathrm{~kg} \mathrm{ha}^{-1}$ ), aplicadas na forma de ureia, e quatro repetições. Cada unidade experimental foi composta por sete plantas e, a área útil, composta pelas cinco plantas centrais, totalizando $240 \mathrm{~m}^{2}$. Em todos os tratamentos, a aplicação de $\mathrm{N}$ foi fracionada em três parcelas iguais, nos meses de outubro, dezembro e fevereiro de cada ano. Para garantir o suprimento de $\mathrm{K} \mathrm{e} \mathrm{P}$, foram aplicadas, em todas as unidades experimentais, doses acima daquelas recomendadas por Raij et al. (1997): $100 \mathrm{~kg} \mathrm{ha}^{-1} \mathrm{de} \mathrm{K}_{2} \mathrm{O}$, parcelados nas mesmas épocas do $\mathrm{N}$, e $50 \mathrm{~kg} \mathrm{ha}^{-1}$ de $\mathrm{P}_{2} \mathrm{O}_{5}$, aplicados em uma única dose, nos meses de outubro de cada ano.

Com base em ensaios preliminares, em que doses de $100 \mathrm{~kg} \mathrm{ha}^{-1}$ de $\mathrm{N}, 25 \mathrm{~kg} \mathrm{ha}^{-1}$ de $\mathrm{P}_{2} \mathrm{O}_{5}$ e $100 \mathrm{~kg} \mathrm{ha}^{-1}$ de $\mathrm{K}_{2} \mathrm{O}$ mantiveram os teores foliares dentro das faixas consideradas adequadas por Stephenson \& Cull (1986) e Raij et al. (1997), o experimento II foi instalado em cinco blocos casualizados, com quatro tratamentos, que consistiram no parcelamento da dose de $500 \mathrm{~kg} \mathrm{ha}^{-1}$ da formulação 20 05-20 (N- $\left.\mathrm{P}_{2} \mathrm{O}_{5}-\mathrm{K}_{2} \mathrm{O}\right)$, em cada ano, correspondente a 2400 g planta ${ }^{-1}$ ano $^{-1}$, das seguintes formas: T1 - uma única aplicação: no mês de outubro; T2 - duas aplicações: nos meses de outubro e dezembro; T3 - três aplicações: nos meses de outubro, dezembro e fevereiro; e, T4 - quatro aplicações: nos meses de outubro, dezembro, fevereiro e abril. Cada unidade experimental foi composta por cinco plantas, sendo a área útil composta pelas três plantas centrais $\left(144 \mathrm{~m}^{2}\right)$.

Os fertilizantes foram aplicados, uniformemente, sob a copa das árvores, nos dois experimentos, e os demais tratos culturais foram semelhantes, em ambos. Foram efetuadas três pulverizações (outubro, dezembro e fevereiro) em cada ano agrícola com $1,8 \mathrm{~kg} \mathrm{ha}^{-1} \mathrm{de} \mathrm{N}$ (ureia), 1,2 $\mathrm{kg} \mathrm{ha}^{-1}$ de $\mathrm{Cu}$ (oxicloreto de cobre), 0,48 $\mathrm{kg} \mathrm{ha}^{-1}$ de $\mathrm{Zn}$ (sulfato de zinco) e $0,2 \mathrm{~kg} \mathrm{ha}^{-1}$ de $\mathrm{B}$ (ácido bórico). O controle de plantas daninhas foi realizado com três roçadas mecanizadas nas entrelinhas e uma aplicação do herbicida glifosato (720 g do i.a. ha-1), em área total, para o preparo da colheita, em cada ano agrícola.
A cada ano, foram coletadas, em setembro, folhas (terceira folha madura) de ramos do terço médio das plantas, nas quatro posições cardeais, totalizando 100 folhas por parcela (Stephenson et al., 1997). Depois de lavadas com água destilada, as folhas foram acondicionadas em sacos de papel, secadas em estufa, com circulação forçada de ar, a $60-70{ }^{\circ} \mathrm{C}$ e, posteriormente, foram moídas, para análise do teor de N, no experimento I, e de N, P e K, no experimento II, seguindo metodologia descrita por Malavolta et al. (1997).

Os frutos abortados foram coletados do solo, aos $30 \mathrm{e}$ 70 dias após a antese e, posteriormente, separados por tamanho (maiores e menores que 1,0 cm de diâmetro) e contados. Os frutos maduros, coletados no chão, entre os meses de fevereiro e maio de cada ano, foram contados e pesados.

Os dados médios de três safras foram submetidos à análise de variância, com o auxílio do programa estatístico SAS (2003). Os efeitos das doses de N (experimento I) foram avaliados por meio de análise de regressão, utilizando-se como critério para escolha do modelo o maior valor do $\mathrm{R}^{2}$, ajustado a $5 \%$ de probabilidade. As médias dos tratamentos de parcelamento da adubação (experimento II) foram comparadas pelo teste de Tukey, a $5 \%$ de probabilidade.

\section{RESULTADOS E DISCUSSÃO}

$\mathrm{O}$ aumento da dose de $\mathrm{N}$ aplicada incrementou o número total de frutos produzidos por planta, até a dose estimada de $168 \mathrm{~kg} \mathrm{ha}^{-1}$ (Figura 1A). Esses resultados demonstram que a deficiência de $\mathrm{N}$ nas plantas de macadâmia reduz a formação de flores e frutos. Stephenson \& Cull (1986) observaram que as plantas de macadâmia que não receberam aplicações de $\mathrm{N}$ apresentaram menor desenvolvimento do caule e dos ramos, além de reduzida emissão e densidade de folhas, gerando, em longo prazo, baixa produtividade da cultura. Stephenson \& Gallagher (1989) verificaram diminuição de floração em plantas que receberam $230 \mathrm{~g}$ ano $^{-1}$ de $\mathrm{N}$, em relação às que receberam $690 \mathrm{~g} \mathrm{ano}^{-1}$ de N. Já Stephenson et al. (1997) acreditavam que o crescimento vegetativo propiciado pela adubação nitrogenada poderia influenciar, negativamente, a produção de nozes, e obtiveram maiores produções em plantas com menores teores de $\mathrm{N}$ nas folhas, mas não conseguiram correlacioná-las com as adubações de solo praticadas $\left(230,690\right.$ e $\left.1150 \mathrm{~kg} \mathrm{planta}^{-1} \mathrm{de} \mathrm{N}\right)$.

O número de frutos abortados por planta não foi afetado pelas doses de $\mathrm{N}$ aplicadas (Figura 1B). A planta de macadâmia faz uso de carboidratos de reservas para o crescimento reprodutivo, enquanto, para o crescimento vegetativo utiliza o $\mathrm{N}$ absorvido do solo (Stephenson et al., 1989). Fletcher et al. (2009) verificaram que as folhas 
do exterior da copa são os principais drenos do $\mathrm{N}$ absorvido pelas raízes durante o período vegetativo; assim, o $\mathrm{N}$ proveniente do solo é inicialmente distribuído para folhas jovens e maduras, que se tornam fontes de $\mathrm{N}$ para flores e frutos, na primavera seguinte, e concluíram que o aumento das doses de $\mathrm{N}$, provavelmente, não influenciam no abortamento de frutos. Por aumentar o total de frutos produzidos por planta e não afetar o número de frutos abortados, o incremento das doses de $\mathrm{N}$ diminuiu a percentagem de frutos abortados (Figura 1C). O aumento das doses de $\mathrm{N}$ incrementou os teores de $\mathrm{N}$ na folha das plantas de macadâmia (Figura 1D). Doses acima de $50 \mathrm{~kg}^{-1} \mathrm{ha}^{-}$ ${ }^{1}$ proporcionaram teores de $\mathrm{N}$, na folha, dentro da faixa considerada por Raij et al. (1997) como adequada para a
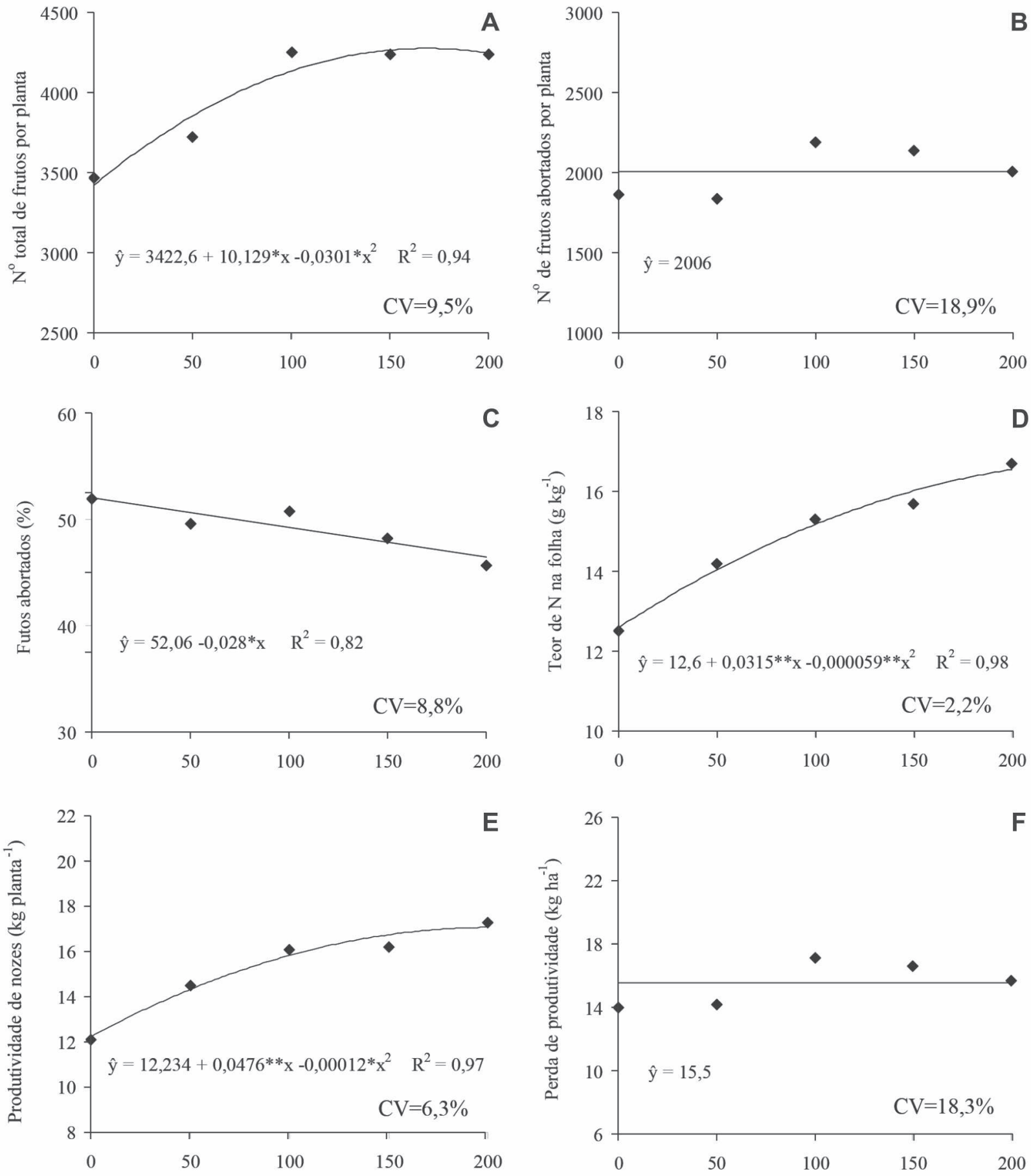

Figura 1. Número total de frutos emitidos por planta (A), número de frutos abortados por planta (B), percentagem de frutos abortados (C), teor de $\mathrm{N}$ na folha (D), produtividade de nozes (E) e perda de produtividade estimada devido ao abortamento (F) da nogueira macadâmia em função, de doses de $\mathrm{N}$ em cobertura. Médias de três anos. * e ** Significativo a 5 e $1 \%$ de probabilidade, respectivamente, pelo teste $t$. 
cultura e doses de 50, 100 e $150 \mathrm{~kg}^{-1} \mathrm{ha}^{-1}$ de $\mathrm{N}$, dentro da faixa ideal para Stephenson \& Cull (1986). Contudo, não houve correlação entre o número de frutos abortados e o teor de $\mathrm{N}$ nas folhas ( $\mathrm{r}=-0,075 \mathrm{~ns})$, confirmando as hipóteses de Fletcher et al. (2009).

Para Rojas et al. (2009), a fase de "pegamento" dos frutos dá-se até 42 dias após a floração, quando os frutos atingem $0,9 \mathrm{~cm}$ de diâmetro, e é seguida do estádio de crescimento dos frutos, que termina com a maturidade fisiológica. Sobierajski et al. (2007) chamaram este de estádio 8 - fase de frutificação efetiva, ou início do crescimento dos frutos. As doses de $\mathrm{N}$ não interferiram na percentagem de frutos abortados prematuramente e a maioria dos frutos foi abortada na fase de pegamento, ou estádio 8, com diâmetro menor que 1,0 cm. Fletcher et al. (2009), em seus estudos com ${ }^{15} \mathrm{~N}$, já haviam pressuposto que o fornecimento de $\mathrm{N}$ não iria interferir no abortamento de frutos em plantas adultas de macadâmia. No experimento I, a percentagem de frutos abortados, que apresentavam diâmetro menor que $1,0 \mathrm{~cm}$, foi de $79,1 \%$, demonstrando que as maiores taxas de abortamento ocorrem no período inicial de desenvolvimento dos frutos (até quatro semanas após a antese), corroborando os resultados observados por McFadyen et al. (2011). Segundo estes autores, os frutos de macadâmia não representam um forte dreno de fotoassimilados, até pelo menos oito semanas após a antese; assim, são vulneráveis, durante o desenvolvimento inicial, à competição por carboidratos com as zonas de crescimento da parte aérea e essa competição causa o abortamento precoce de frutos.

Por causa do aumento do número total de frutos emitidos por planta (Figura 1A) e da redução da percentagem de abortamento (Figura 1C), as doses de N proporcionaram incremento da produtividade de nozes por planta (Figura 1E). A produtividade máxima de nozes foi obtida com dose estimada de $198 \mathrm{~kg} \mathrm{ha}^{-1}$ de $\mathrm{N}$, o que equivale a $2,2 \mathrm{~kg}$ planta $^{-1}$ ano $^{-1}$ de ureia. Para Stephenson et al. (1997), altas produtividades de nozes na cultura da macadâmia estão associadas a quantidades equilibradas de $\mathrm{N}$ nas plantas e eles recomendam até $1 \mathrm{~kg}$ planta $^{-1}$ ano $^{-1}$ de ureia. Contudo, doses excessivas de $\mathrm{N}$ podem promover desequilíbrio e culminar em redução da produtividade (Fletcher et al., 2009). Segundo Stephenson \& Cull (1986), o N favorece o crescimento vegetativo da planta, sendo necessário para prover desenvolvimento de ramos e folhas, que possibilitam a formação de mais frutos e atendem a demanda de fotoassimilados desses frutos. Entretanto, as nogueiras macadâmia necessitam manter um equilíbrio entre o desenvolvimento vegetativo e reprodutivo e a vegetação excessiva pode competir com os frutos em desenvolvimento e reduzir a produtividade.

Considerando-se o peso médio dos frutos colhidos e o número de frutos abortados por planta, foi possível es- timar a perda de produtividade ocorrida em função do abortamento. Independentemente da dose de $\mathrm{N}$ utilizada, cada planta de macadâmia deixou de produzir em média $15,5 \mathrm{~kg}$ de nozes, por abortamento de frutos (Figura 1F).

O parcelamento da adubação NPK, feito em pelo menos duas vezes, ou seja, aplicação em outubro e dezembro, proporcionou maior número total de frutos por planta (Tabela 1). De acordo com Stephenson et al. (1997), o parcelamento dessa adubação torna disponíveis os elementos à planta na fase de acúmulo de óleo. $\mathrm{O}$ fornecimento parcelado do $\mathrm{N}$ evita o estímulo a fluxos vegetativos, mas mantém teores suficientes de $\mathrm{N}$ e reservas de carboidratos para sustentar os frutos (Stephenson \& Gallagher, 1989). A nutrição adequada da planta de macadâmia, especialmente em N, favorece o crescimento vegetativo, sendo necessária para prover desenvolvimento de ramos e folhas que possibilitem a formação de mais frutos e atendam à sua demanda de fotoassimilados (Stephenson \& Cull, 1986).

O potencial produtivo da macadâmia é determinado desde a iniciação floral até a maturação dos frutos; assim, o desenvolvimento do botão floral, o "pegamento" e o desenvolvimento dos frutos são fatores que poderiam ser influenciados pelos níveis de nutrientes na planta durante a fase reprodutiva. Porém, não se verificou diferença significativa para o número de frutos abortados, para os diversos parcelamentos da adubação NPK estudados (Tabela 1). O número médio de frutos abortados, considerando-se os três anos agrícolas, foi de 1937,5 frutos planta ${ }^{-1}$. Apesar de não haver diferenças para o número de frutos abortados por planta, a percentagem de frutos abortados foi menor, quando foi realizado parcelamento da adubação NPK, graças ao maior número total de frutos por planta (Tabela 1). Esses resultados evidenciam que, apesar de não interferir no número de frutos abortados, o parcelamento da adubação aumenta o número de frutos emitidos e, consequentemente, o número de frutos retidos por planta, levando a maiores pordutividade de nozes.

Stephenson et al. (1997) estudaram o parcelamento das adubações de N (um, dois, três, quatro e doze parcelas ano ${ }^{-1}$ ) e constataram que o $\mathrm{N}$ nas folhas mantém-se dentro de níveis considerados adequados, durante todo o ano, mesmo no tratamento com uma única aplicação. Neste trabalho, o não parcelamento da adubação NPK proporcionou teor de $\mathrm{N}$ na folha menor que o do parcelamento em três ou quatro aplicações. No tratamento sem parcelamento da adubação, o teor de $\mathrm{N}$ na folha ficou abaixo da faixa considerada adequada por Raij et al. (1997). Contudo, como constatado no experimento I, não houve correlação entre o número de frutos abortados e o teor de $\mathrm{N}$ na folha $(\mathrm{r}=-0,204 \mathrm{~ns})$. Os teores de $\mathrm{P}$ e K nas folhas não foram afetados pelo parcelamento da adubação NPK e apresentaram valores médios de 0,95 e 7,25 para $\mathrm{P}$ e $\mathrm{K}$, respectivamente. 
Tabela 1. Número total de frutos emitidos por planta, número de frutos abortados por planta, percentagem de frutos abortados, teor de $\mathrm{N}$ na folha, produtividade de nozes e perda de produtividade estimada devido ao abortamento da nogueira macadâmia em função do parcelamento da adubação NPK de cobertura. Médias de três anos

\begin{tabular}{lcccccc}
\hline $\begin{array}{c}\text { Parcelamento } \\
\text { da adubação } \\
\text { NPK }^{(\mathbf{1})}\end{array}$ & $\begin{array}{c}\text { No total } \\
\text { de frutos } \\
\text { emitidos por } \\
\text { planta }\end{array}$ & $\begin{array}{c}\text { No de frutos } \\
\text { abortados } \\
\text { por planta }\end{array}$ & $\begin{array}{c}\text { Frutos } \\
\text { abortados } \\
(\%)\end{array}$ & $\begin{array}{c}\text { Teor de } \mathbf{N} \\
\text { na folha } \\
\left(\mathbf{g ~ k g}^{-1}\right)\end{array}$ & $\begin{array}{c}\text { Produtividade } \\
\text { de nozes } \\
\left(\mathbf{k g ~ p l a n t a}^{-1}\right)\end{array}$ & $\begin{array}{c}\text { Perda de } \\
\text { produtividade } \\
\text { estimada } \\
\left(\mathbf{k g ~ p l a n t a}^{-1}\right)\end{array}$ \\
\hline $\mathrm{T} 1$ & $3.855 \mathrm{~b}$ & $2.046 \mathrm{a}$ & $52,0 \mathrm{a}$ & $14,5 \mathrm{~b}$ & $14,1 \mathrm{~b}$ & $16,0 \mathrm{a}$ \\
$\mathrm{T} 2$ & $4.663 \mathrm{ab}$ & $1.933 \mathrm{a}$ & $39,5 \mathrm{~b}$ & $15,4 \mathrm{ab}$ & $20,9 \mathrm{a}$ & $14,8 \mathrm{a}$ \\
$\mathrm{T} 3$ & $4.810 \mathrm{a}$ & $2.087 \mathrm{a}$ & $39,4 \mathrm{~b}$ & $15,9 \mathrm{a}$ & $20,8 \mathrm{a}$ & $15,8 \mathrm{a}$ \\
$\mathrm{T} 4$ & $4.278 \mathrm{ab}$ & $1.684 \mathrm{a}$ & $36,8 \mathrm{~b}$ & $15,9 \mathrm{a}$ & $20,1 \mathrm{a}$ & $13,1 \mathrm{a}$ \\
\hline $\mathrm{CV}(\%)$ & 10,9 & 20,9 & 11,1 & 8,5 & 10,9 & 20,5 \\
\hline
\end{tabular}

Médias seguidas de letras iguais nas colunas não diferem entre si pelo teste Tukey, a 5\% de probabilidade. ${ }^{(1)}$ Parcelamento da dose de $500 \mathrm{~kg}$ ha-1 da formulação $\mathrm{N}-\mathrm{P}_{2} \mathrm{O}_{5}-\mathrm{K}_{2} \mathrm{O}$ 20-05-20 em cada ano: T1 - uma única aplicação em outubro T2 - duas aplicações em outubro e dezembro T3 - três aplicações em outubro, dezembro e fevereiro e, T4 - quatro aplicações em outubro, dezembro, fevereiro e abril.

Assim como no experimento anterior, as maiores taxas de abortamento foram verificadas nas primeiras semanas após a antese, com média de 75,8 \% dos frutos abortados com diâmetros menores que $1,0 \mathrm{~cm}$, porém, sem efeito dos tratamentos nessa variável. Dessa forma, evidenciou-se que a fase inicial de desenvolvimento do fruto é a fase crítica para o abortamento, confirmando as hipóteses de McFadyen et al. (2011) e que, nela, devem-se concentrar os esforços de pesquisa para retenção de frutos, com vistas ao aumento das produtividades.

Os tratos culturais utilizados no Brasil são adaptações de pesquisas desenvolvidas na Austrália e nos Estados Unidos (Sacramento \& Pereira, 2003). A produtividade da cultura da macadâmia depende dos tratos culturais, das variedades e do adensamento de plantio, e pode chegar a $35 \mathrm{~kg}$ planta $^{-1}$ ano $^{-1}$ (Sobierajski et al., 2006). Porém, as produtividades obtidas neste trabalho, assim como as médias de produção dos produtores brasileiros, são muito inferiores à produtividade mencionada acima; portanto, observase uma produtividade nacional baixa, aquém da capacidade produtiva da espécie (Pimentel, 2007). A média de frutos abortados para todos os tratamentos, durante as três safras consideradas, foi de 1.972 frutos planta ${ }^{-1}$. Considerando-se o peso médio dos frutos colhidos neste experimento, podemos estimar que os frutos abortados prematuramente representariam um acréscimo de produtividade de 15,3 kg planta $^{-1} \mathrm{e}$, caso não fossem abortados, elevariam a produção em 89\%, aproximando-a das previsões mais otimistas colocadas pelos autores citados.

Este é o primeiro relato brasileiro, sobre a quantidade e o tamanho de frutos de noz macadâmia, abortados prematuramente. A quantidade de frutos abortados é próxima àquela de frutos produzidos e a maior parte dos frutos da nogueira macadâmia é abortada no início de seu desenvolvimento. Essas são importantes informações para futuras pesquisas relacionadas ao aumento de produtividade, uma vez que a redução do abortamento tem reflexo direto na produção de frutos. Pesquisas relacionadas com a retenção de frutos nas fases mencionadas, como, por exemplo, pulverizações de reguladores vegetais ou maior suprimento com nutrientes relacionados com a fixação das estruturas reprodutivas, como cálcio e boro (Malavolta et al., 1997), poderão ser alternativas para elevar as produtividades das lavouras nacionais e proporcionar maior rentabilidade e desenvolvimento à macadamicultura brasileira.

\section{CONCLUSÕES}

A aplicação de N, bem como o parcelamento da adubação NPK de cobertura, em pelo menos duas vezes (outubro e dezembro), não alteraram o número de frutos abortados por planta de macadâmia, mas, por aumentarem o número total de frutos emitidos e reduzirem a percentagem de abortamento, proporcionaram maior produtividade de nozes.

\section{REFERÊNCIAS}

Cha-um S, Chanseetis C, Chintakovid W, Pichakum A \& Supaibulwatana K (2011) Promoting root induction and growth of in vitro macadamia (Macadamia tetraphylla L. 'Keaau') plantlets using $\mathrm{CO}_{2}$-enriched photoautotrophic conditions. Plant Cell, Tissue and Organ Culture, 106:435-444.

CATI - Coordenadoria de Assistência técnica Integral (2007/2008) Levantamento das unidades de produção agropecuária, estatísticas agrícolas, Estado de São Paulo (2007/2008) Projeto LUPA. Disponível em: http://www.cati.sp.gov.br/projetolupa/>. Acessado em: 10 de abril de 2012.

Dalastra IM (2010) Germinação de sementes de nogueiramacadâmia submetidas à incisão e imersão em ácido giberélico. Ciência e Agrotecnologia, 34:641-645.

Fletcher A, Rennenberg H \& Schmidt S (2009) Nitrogen partitioning in orchard-grown Macadamia integrifolia. Tree Physiology, 30:244-256.

Huett DO (2004) Macadamia physiology review: a canopy light response study and literature review. Australian Journal of Agricultural Research, 55:609-624. 
Malavolta E, Vitti GC \& Oliveira SA (1997) Avaliação do estado nutricional de plantas: princípios e aplicações. $2^{\mathrm{a}}$ ed. Piracicaba, Potafos. 319p.

McFadyen LM, Robertson D, Sedgley M, Kristiansen P \& Olesen $\mathrm{T}$ (2011) Post-pruning shoot growth increases fruit abscission and reduces stem carbohydrates and yield in macadamia. Annals of Botany, 107:993-1001.

McFadyen LM, Robertson D, Sedgley M, Kristiansen P \& Olesen $T$ (2012) Effects of the ethylene inhibitor aminoethoxyvinylglycine (AVG) on fruit. Scientia Horticulturae, 137:125-130.

Olesen T (2005) The timing of fluxingdevelopment affects the flowering of avocado (Persea Americana) and macadamia (Macadamia integrifolia $x$ tetrapyilla). Australian Journal of Agricultural Research, 56:723-729.

Perdoná MJ \& Suguino E (2008) Macadâmia: A Rainha das Nozes. Revista Painel, 11:18.

Pimentel LD \& Santos CEM, Wagner Júnior A, Silva VA \& Bruckner CH (2007) Estudo de viabilidade econômica na cultura da nozmacadâmia no Brasil. Revista Brasileira de Fruticultura, 29:500507 .

Pimentel LD (2007) A cultura da macadâmia. Revista Brasileira de Fruticultura, 29:414-416.

Quaggio JA \& Raij B van (1997) Frutiferas. In: Raij B van, Cantarella H, Quaggio JA \& Furlani AMC (Eds.) Recomendações de adubação e calagem para o Estado de São Paulo. Campinas, IAC. p.124-142. (Boletim Técnico, 100).

Rojas CM, Garcia CV, Muños ME \& Rojas LDG (2009) Fenología de ûoración y fructiûcación en Macadamia integrifolia. Acta Agronômica, 58:277-284.
Sacramento CK \& Pereira FM (2003) Fenologia da floração da nogueira macadâmia (Macadamia integrifolia Maiden e Betche) nas condições climáticas de Jaboticabal, São Paulo, Brasil. Revista Brasileira de Fruticultura, 25:19-22.

Sobierajski GR, Francisco VLFS, Rocha P, Ghilardi AA \& Maia ML (2006) Noz-Macadâmia: produção, mercado e situação no Estado de São Paulo. Informações Econômicas, 36:25-36.

Sobierajski GR, Barbosa W, Bettiol Neto JE, Chagas EA \& Campos-Dall'Orto FA (2007) Caracterização dos estágios fenológicos em sete cultivares e seleções de nogueira-macadâmia. Revista Brasileira de Fruticultura, 29:690-694.

SAS Institute Inc. (2003) Statistical Analysis System user's guide. Version 9.1. Cary, 2003. CD-ROM.

Stephenson RA \& Cull BW (1986) Standard leaf nutrient levels for bearing macadamia trees in southeast Queensland. Scientia Horticulturae, 30:73-82.

Stephenson RA \& Gallagher EC (1989) Timing of nitrogen application to macadamias 3. Reproductive growth, yield and quality. Australian Journal of Experimental Agriculture, 29:581585 .

Stephenson RA, Gallagher EC \& Doogan VJ (1997) Leaf nitrogen as a guide for fertilizing macadamia. Australian Journal of Experimental Agriculture, 37:599-604.

Stephenson RA, Rasmussenb TS \& Gallagher EC (1989) Timing of nitrogen application to macadamias 2. Storage carbohydrates. Australian Journal of Experimental Agriculture, 29:575-579. 